\title{
Dewatering System Control by MATLAB Software
}

\author{
Omar Y. Mohammed ${ }^{1, a^{*}}$ and Ammar A. Shiekha ${ }^{1, b}$ \\ ${ }^{1}$ Department of Civil Engineering, University of Baghdad, Baghdad, Iraq. \\ â.mohammed1901m@,coeng.uobaghdad.edu.iq , aa
}

\begin{abstract}
The aim was to design a MATLAB program to calculate the phreatic surface of the multiwell system and present the graphical shape of the water table drawdown induced by water extraction. Dupuit's assumption is the base for representing the dewatering curve. The program will offer the volume of water to be extracted, the total number of wells, and the spacing between them as well as the expected settlement of soil surrounding the dewatering foundation pit. The dewatering well arrangement is required in execution works, and it needs more attention due to the settlement produced from increasing effective stress.
\end{abstract}

Keywords: Dewatering; settlement; MATLAB; groundwater control.

\section{Introduction}

In many places, land subsidence has occurred, especially in heavily populated areas worldwide [1]. Due to high population intensity, many buildings are adjacent to each other in the same block area. These factors increased the propensity to create high-rise buildings. Many of these modern highrise developments are constructed next to existing old buildings. The neighboring old building is typically critical either because the building construction framework's weakness or the foundation's level is shallow. High-rise buildings with basements require deeper excavation than the neighboring building's foundation floor with the presence of shallow neighboring foundations [2]. Within urban environments, the geotechnical role becomes crucial to assess the implications of changing the groundwater levels and propose and implement additional safety elements or measures. In many cases, groundwater control is essential to prevent or minimize the expected detrimental effects on existing adjacent buildings and other structures. [3]. The buildings inside the surroundings of the extraction well area produce damage in some sections. In extreme situations, this causes can be lead the underground pipes to fracture [4].

Construction excavations and permanent structures below the water table that are not waterproof or are waterproof but not built to withstand hydrostatic pressure are common reasons to lower groundwater levels. When planning building beneath the water table, choices for dealing with this problem include building "in the wet" i.e., there is still water or some other kind of fluid in the excavation. During building, cutoff walls are used to restrict inflow into the excavation, or groundwater levels are lowered to minimize hydraulic head and thus inflow into the excavation. Dewatering within the confinement of the cutoffs may still be needed to improve the stability of working areas even when cutoff walls are used, albeit to a lesser degree. Methods of dewatering involve passively accumulating excess water inflow into an excavation and actively lowering water levels to keep inflow into an excavation within acceptable limits [5].

In general, MATLAB program is one of the essential programs for engineers and deals mainly with matrices and can solve engineering problems and will be used in this paper to represent water withdrawal and land subsidence. The essential objective is to develop an interactive computer-to-user communication software with as little assistance as possible, enabling learning objectives to be met in less time than required. In this meaning, the programming of these programs in MATLAB software allows the user to choose from a vast number of parameters related to model programming and design to determine their potential impact on numerical results. The study aims to present a computer program that can be used in a simple manner by the engineers in order to estimate the amount of water to be extracted from the ground to reach the required level of groundwater which is not less than 0.5 $\mathrm{m}$ under foundation, such a program is very useful to calculate and to repeated calculation, till 
reaching the requirement of the dewatering and to predicted the radius of influence which affects the dewatered area, since the dewatering causes a change in the value of effective stress.

\section{Dewatering Process}

Dewatering is the method of extracting water from the soil or completely extracting the water from a specific construction site. Several excavations are carried beneath groundwater level; techniques for dealing with these problems depend on the groundwater control requirements, the excavation dimensions, and the soil type, among other factors. Dewatering operations of the simplest kind are carried out with little planning. Operations in difficult environments necessitate the use of specialized engineering and construction techniques [6]. It is normal practice to lower the groundwater level before construction in order to promote the excavation works in the project. This is achieved by extracting water from aquifers by dewatering wells. However, this activity can cause ground settlement in the vicinity of an excavation, causing tilt or even cracking of nearby structures [7]. For a long time, building dewatering has been a specialized industry. As a result, a number of well-established techniques for lowering the groundwater table during excavation have been created. Dewatering technology is influenced by geology, groundwater levels, and the type of excavation.

Sumps, wells, and well points are the most popular dewatering methods. Sumps perform best in fine-grained soils or coarse boulder deposits; pumping from perforated drums or casings in a gravelfilled backhoe pit provides localized, very shallow dewatering (less than 3 feet) [6]. Wells are largediameter (greater than 6 inches) holes with slotted casings and downhole pumps that are drilled relatively deep (greater than 10 feet). Wells perform best in sand-based or sand-and-gravel-based soils, and they can dewater vast areas to great depths. Well points are shallow wells with a small diameter (less than 6 inches) and are closely spaced ( 2 to 10 feet apart). Well points dewater coarse sands and gravels, as well as silts and clays, efficiently. They can be used in a variety of ways. On the other hand, well points use a vacuum system and have a maximum depth of around 25 feet. Wellpoint systems are more expensive than sumps or wells, and they require near-constant maintenance. When a well is pumped, the surrounding groundwater surface is lowered, which is dependent on the well size, soil permeability, pumping rate, and distance from the well. Pumping tests from the well can be used to assess the average hydraulic conductivity of a soil credit in the path of flow in the region.

A suitable mechanical device should be selected for those conditions once the total flow, Q, the necessary vacuum, the distance to the point of discharge, and the discharge elevation have been calculated. Depending on equipment availability and job conditions, a single pump or multiple pumps can be used. If more than one pump is used, they should be spaced evenly along the header or clustered into a single pump station. Only one discharge line is used in a single pump station, but long header pipes are used to transport the water to the central pump station without causing undue friction, as shown in Figure 1.

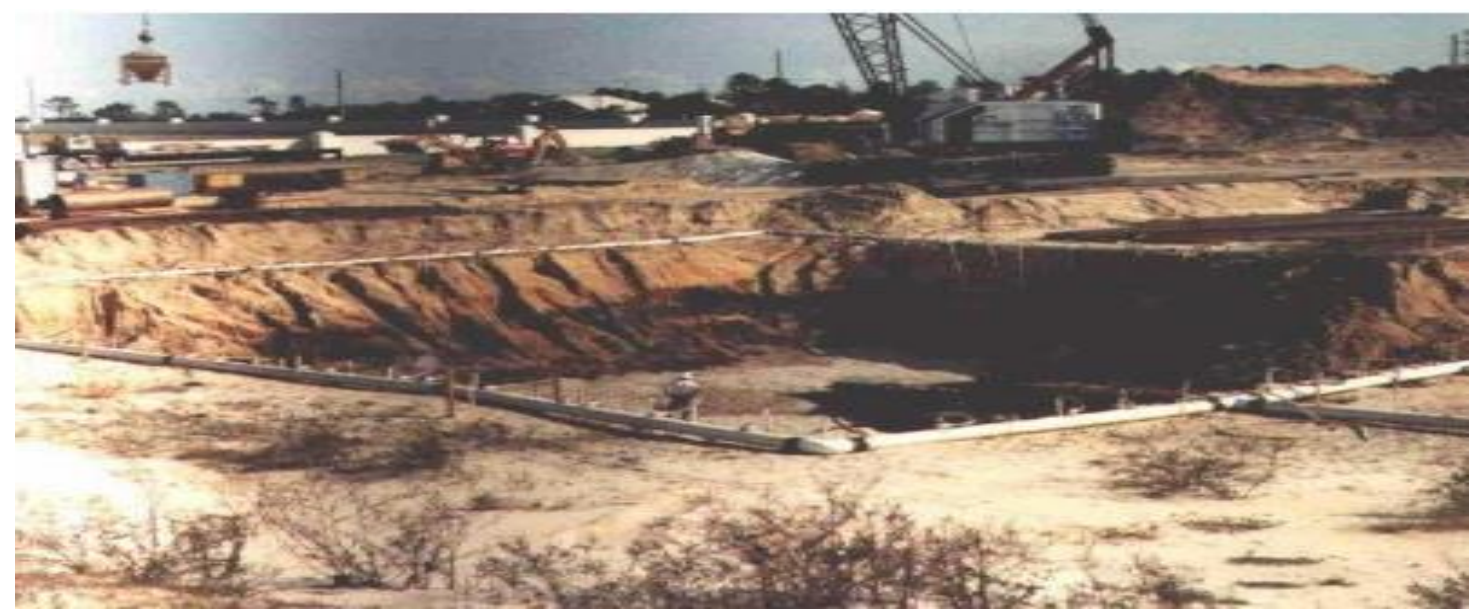

Figure 1. Construction well points system dewatering. 


\section{Numerical Analysis of Dewatering Process}

Li and Yang [8] used FLAC software to model a building, taking into account the foundation's and surrounding soil's mutual effects. In the numerical analysis, both dewatering and excavation are taken into account. The findings revealed that the dewatering process in the excavation foundation has a direct impact on excavation foundation behavior, with water seepage increasing wall deflection and deforming the basal base while reducing the water level outside the excavation product vertical consolidation. Budihardjo et al. [9] describe the effect of settlement as a result of the dewatering. Various layers of clay of various thicknesses and wells in various places are examined as part of the analysis Plaxis 2D is used to analyze the data. The findings show that changes in groundwater can cause the surface of each simulated aquifer sand to deform.

Samaaneh and Gadhib [10] describe the effect of dewatering on the building was analyzed using the finite element method. The analysis was carried out in the eastern region of Saudi Arabia, where the water level is high in this region, lead a negative impact on the building's capacity. Wells are used to keeping the foundations of various buildings and structures dry by lowering the water level. The research-based on a numerical analysis using SAP 2000 for the analysis of buildings and structures subjected to water shortage issues, concluding that building settlements caused a redistribution of stresses in beams and columns, which influenced building design. It means that the influence of the dewatering process plays a significant role in the appearance of deformation in building components. García-Ros et al. [11] explain the program emulates consolidation with Vertical Drains, which is a tool for solving in heterogeneous soils with totally or partially penetrating prefabricated vertical drains. The code Next-Generation Simulation Software with Integrated Circuit Focus was used as a computational method, while the Matrix Laboratory (MATLAB) code was used to program and construct an interface with the user via interactive screens in order to provide a fully free program. Akgun et al. [12] used the program "MamLand"' and developed to construct a Mamdani fuzzy inference system and employed it in MATLAB. It is possible to create a landslide susceptibility map based on expert opinion using this newly developed software. The Mamdani FIS was used to assess landslide conditioning data, and a file depicting the landslide susceptibility degrees for the study area was developed. For the study area, a landslide inventory dataset with 351 landslide locations was obtained. The data were processed using a soft computing approach, i.e., a Mamdani-type fuzzy inference method, after the data processing stage of the study was completed. The FIS in this study included seven conditioning parameters that describe topographical, geological, and environmental conditions. These degrees were then imported into a GIS setting, where a landslide susceptibility map was created and evaluated for statistical purposes.

Yousef et al. [13] described three scenarios using the MATLAB interface to predict groundwater levels in the Karaj study area until the water year 2023-2024: optimistic, pessimistic, and continuing current situation. The current continuing situation, negative situation, and positive situation, respectively, 12.834, 19.089, and $4.906 \mathrm{~m}$ water level drops were computed. Wang et al. [14] used MODFLOW to build the groundwater flow numerical simulation modeling. A complex assessment framework for groundwater resources under internet conditions was completed using GIS. A water budget was evaluated during the construction of the groundwater model, which revealed a negative budget in the NCP. The original data, including graphs and attribution data, could be stored in the database in this integrated framework. These data were converted into files that the MODFLOW core software could read when the process of assessing and predicting groundwater flow began. The measured water level and drawdown could be viewed and analyzed on the internet. The simulation period was from 1 January 2002 to 31 December 2003. The overall recharge of the groundwater system during this period was $49,374 \times 10^{6} \mathrm{~m}^{3}$, and the total discharge was $56,530 \times 10^{6} \mathrm{~m}^{3}$.

\section{Dewatering Computation During Excavation}

When the seepage field's boundary is impermeable, the flow line is parallel to the boundary inside the flow net, and if the seepage field is the same water head boundary, the flow line is perpendicular to the seepage boundary as shown in Figure 2. The enclosure structure and the impermeable stratum 
underneath it can be viewed as impermeable borders, and the groundwater's horizontal velocity is more significant than its vertical value under the enclosure's structure. Thus, groundwater seepage at various depths beneath the enclosure structure's center axis is roughly known as a laminar flow. The water headline is vertical at the bottom of the enclosure construction central axis. Moreover, the inflow area around the excavation is divided into two inflow fields according to these vertical flow lines, one inside the excavation and the other outside the excavation. The inflow of water from the two seepage fields can then be separately resolved [15-17].

$\mathrm{Q}_{1}=\mathrm{Q}_{2}$

Where

$\mathrm{Q}_{1}$ : The groundwater inside the excavation

$\mathrm{Q}_{2}$ : The groundwater outside the excavation

The radius of influence is known as the maximum distance between two points which the normal measurement devices in the field can detect the drawdown. The most popular method of determining the radius of influence is to use empirical formulas such as Sichardt's formula as well as Kusakin's formula. Furthermore, In the formulae, some scholars often take into account related impact factors such as time $t$ and radius of the excavation $\left(\mathrm{r}_{\mathrm{e}}\right)$ [18-20].

$$
\mathrm{R}=2 \mathrm{~S}_{\mathrm{w}} \sqrt{\mathrm{Hk}}
$$

Where, R: radius of influence, $\mathrm{m} ; \mathrm{S}_{\mathrm{w}}$ : depth of groundwater the well, $\mathrm{m} ; \mathrm{H}$ : the aquifer's depth, $\mathrm{m}$; $\mathrm{k}$ : permeability coefficient $\mathrm{cm} / \mathrm{s}$

The inflow of water $\mathrm{Q}_{2}$ is determined for a circular or rectangular excavation with a length-towidth ratio of less than 20 , use the following equation [21].

$$
\begin{aligned}
& \mathrm{Q}_{2}=\frac{1.366 \mathrm{~K}\left(\mathrm{H}^{2}-\mathrm{h}_{\mathrm{m}}^{2}\right)}{\lg \left(1+\left(\frac{\mathrm{R}}{\mathrm{r}_{\mathrm{o}}}\right)\right)+\left(\left(\frac{\mathrm{h}_{\mathrm{m}}-\mathrm{J}}{\mathrm{J}}\right) \lg \left(1+0.2\left(\frac{\mathrm{h}_{\mathrm{m}}}{\mathrm{r}_{\mathrm{o}}}\right)\right)\right)} \\
& \mathrm{h}_{\mathrm{m}}=\frac{\mathrm{H}+\mathrm{h}^{\prime}}{2}
\end{aligned}
$$

Where, $r_{o}=0.565 \sqrt{A_{o}}, r_{0}$ : equivalent radius of the excavation, $m ; A_{o}$ : excavation area $\left(\mathrm{m}^{2}\right)$, $h^{\prime}$ : water head (m); J: length of the water inside well. The distribution of seepage fields in Figure 2 is simplified to one-dimensional distribution according to Darcy's seepage experimental conditions, as shown in Figure 3.

$$
\begin{aligned}
& \mathrm{Q}_{1}=\frac{\mathrm{KA}\left(\mathrm{h}^{\prime}-\mathrm{h}\right)}{\mathrm{L}} \\
& \mathrm{A}=\frac{\mathrm{V}}{\mathrm{L}^{\prime}} \\
& \mathrm{V}=\pi \mathrm{r}_{\mathrm{o}}^{2}\left(\mathrm{l}_{2}+\mathrm{l}_{3}\right) \\
& \mathrm{L}=\frac{\left(2 \mathrm{l}_{2}+\mathrm{l}_{3}+\mathrm{r}_{\mathrm{o}}\right)}{2} \\
& \mathrm{H}=\mathrm{l}_{1}+\mathrm{l}_{2}+\mathrm{l}_{3} \\
& \mathrm{~h}=\mathrm{l}_{2}++\mathrm{l}_{3} \\
& \mathrm{~S}_{\mathrm{w}}=\mathrm{H}-\mathrm{h}
\end{aligned}
$$

Where: h: after dewatering water head in excavation $(\mathrm{m}) ; l_{1}$ : lowering the water table in excavation $(\mathrm{m}) ; l_{2}$ : after dewatering, the spread between the water table and the ground $(\mathrm{m}) ; l_{3}$ :distance from bottom enclosure structure to impermeable stratum $(\mathrm{m})$; A: cross-sectional area $\left(\mathrm{m}^{2}\right)$; V: total seepage $\left(\mathrm{m}^{3}\right)$; L: seepage path. 


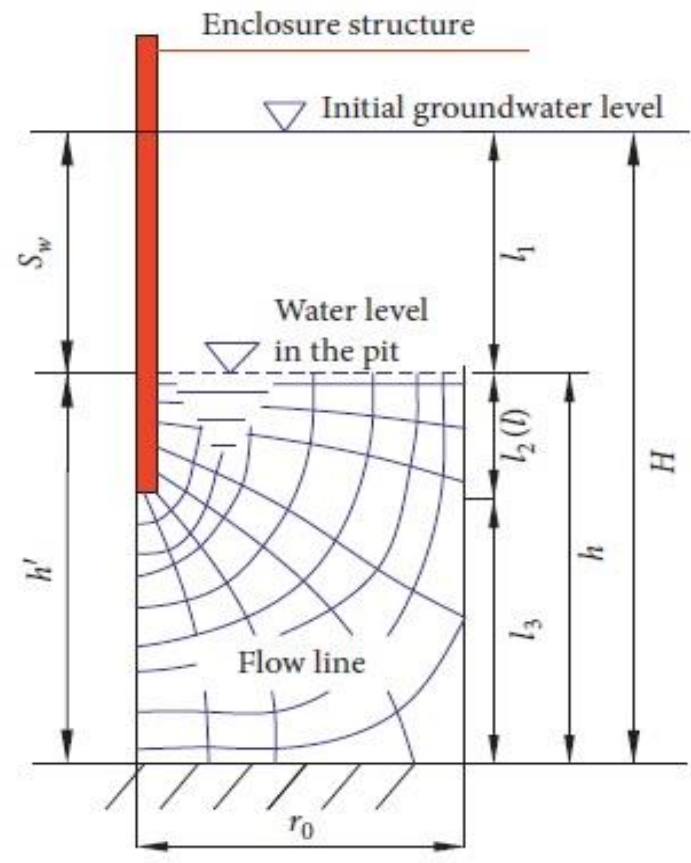

Figure 2. Distribution of seepage fields in excavation

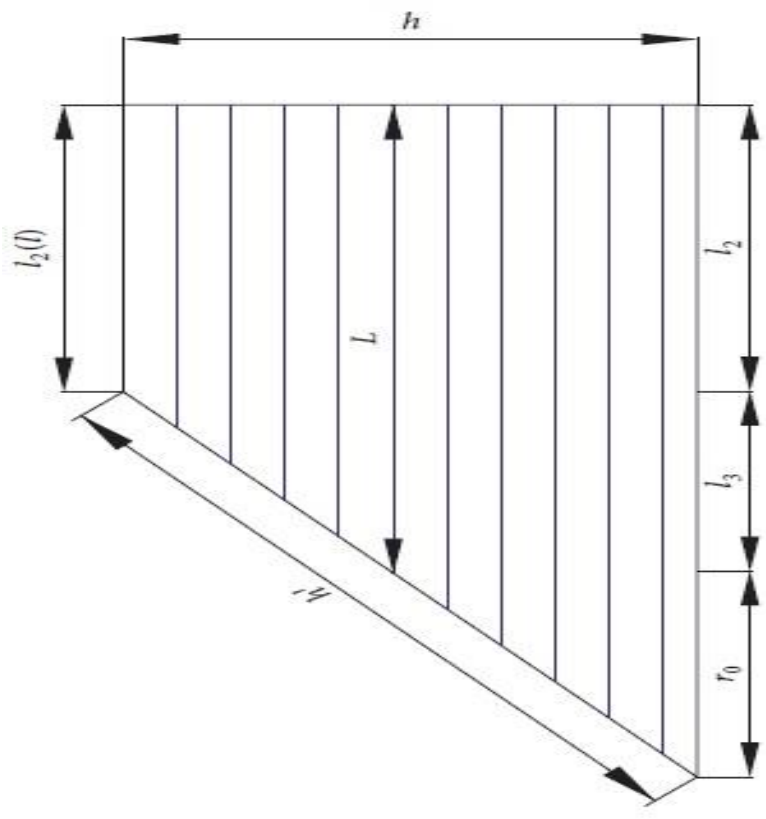

Figure 3. Simplification of the seepage path in excavation

Eqs. 1 to 11 have a simultaneous solution, which leads to the following equation:

$$
\frac{4 \pi \mathrm{r}_{\mathrm{o}}^{2}\left(\mathrm{l}_{2}+\mathrm{l}_{3}\right)\left(\mathrm{h}^{\prime}-\mathrm{h}\right)}{\left(2 \mathrm{l}_{2}+\mathrm{l}_{3}+\mathrm{r}_{\mathrm{o}}\right)^{2}}=\frac{0.3415\left[4 \mathrm{H}^{2}-\left(\mathrm{H}+\mathrm{h}^{\prime}\right)^{2}\right]}{\lg \left[1+\left(\frac{2\left(\mathrm{H}-\mathrm{h}^{\prime}\right) \sqrt{\mathrm{HK}}}{\mathrm{r}_{\mathrm{o}}}\right)\right]+\left(\frac{\mathrm{H}+\mathrm{h}^{\prime}-2 \mathrm{l}}{2 \mathrm{l}}\right) \lg \left(1+\left(\frac{\mathrm{H}+\mathrm{h}^{\prime}}{10 \mathrm{r}_{\mathrm{o}}}\right)\right)}
$$

To determine the number of dewatering wells:

$$
\begin{aligned}
& \mathrm{n}=\frac{\mathrm{Q}_{1}}{\mathrm{q}_{\mathrm{o}}} \\
& \mathrm{D}=\frac{\mathrm{L}}{\mathrm{n}}
\end{aligned}
$$

Where D: the distance between well points (m); L: surroundings of an excavation (m); n: number of well points.

\section{The Simulation Program}

The simulation of the $3 \mathrm{D}$ environment is the aim of this program dewatering problem in soils formed by one stratum and considering the impact of the dewatering on an adjacent building. It is an easy-touse program that is capable of performing complex numerical computation. This requirement necessitates developing a functional and easy graphical interface in which data entry and option selection are made in a logical, intuitive, and directed manner. About the simulation potentials, the user should make use of the program to design a dewatering system, since the software helps us to easily learn about a wide range of outcomes, enabling engineers to make the best decisions possible.

Simulation Input Data. Data entry is carried out through the following window that appears as completed in Figure 4. The start-up screen allows the entry of the problem geometry, the definition of the circumference excavation in meter, the permeability of soil in cube meter per second, the thickness of aquifer in meter, required drawdown under the foundation in meter, and discharge for every well in cube meter per day. The user can prevent entering data by operating with a previously saved file to improve the program's stability and effectiveness. The software allows you to save and load data for this purpose. The simulation will begin once all of the data has been input or loaded. To 
accomplish this work, the program generates a network model file from a particular source code executed within the program.

Simulation Output Data. The user can view the results at the end of the simulation. At the end of the simulation, the user can access the results given in Mathematically as shown in Figure 5 and a graphic way as shown in Figure 6. The program offers up to total discharge in a site in cube meter per day and the number of wells that required for drawdown under foundation, the distance between it's well, and that the geotechnical engineer can have all the necessary information in a simple, influence radius (which represent the radius of equivalent area), conveniently arranged precise form.

\section{Results and Discussion}

The results obtained by the numerical analysis by MATLAB software reflected the site in the example assumed is need to draw down groundwater to $2 \mathrm{~m}$ under the foundation, and the parameter site is circumference excavation is $300 \mathrm{~m}$, soil permeability equal $0.0003 \mathrm{~cm} / \mathrm{second}$, the thickness of aquifer was $20 \mathrm{~m}$. After used well have a diameter of $0.3 \mathrm{~m}$ and a pump with a capacity of $13 \mathrm{~m}^{3} /$ day. The findings revealed that during the dewatering process in the excavation foundation was the total discharge in site $40 \mathrm{~m}^{3} /$ day, and the number of wells for this must be 3 , and the distance between it was $374 \mathrm{~m}$ and the radius of influence $935 \mathrm{~m}$.and a surface was obtained on a three-dimensional surface representing the groundwater drop for each point of the excavation.

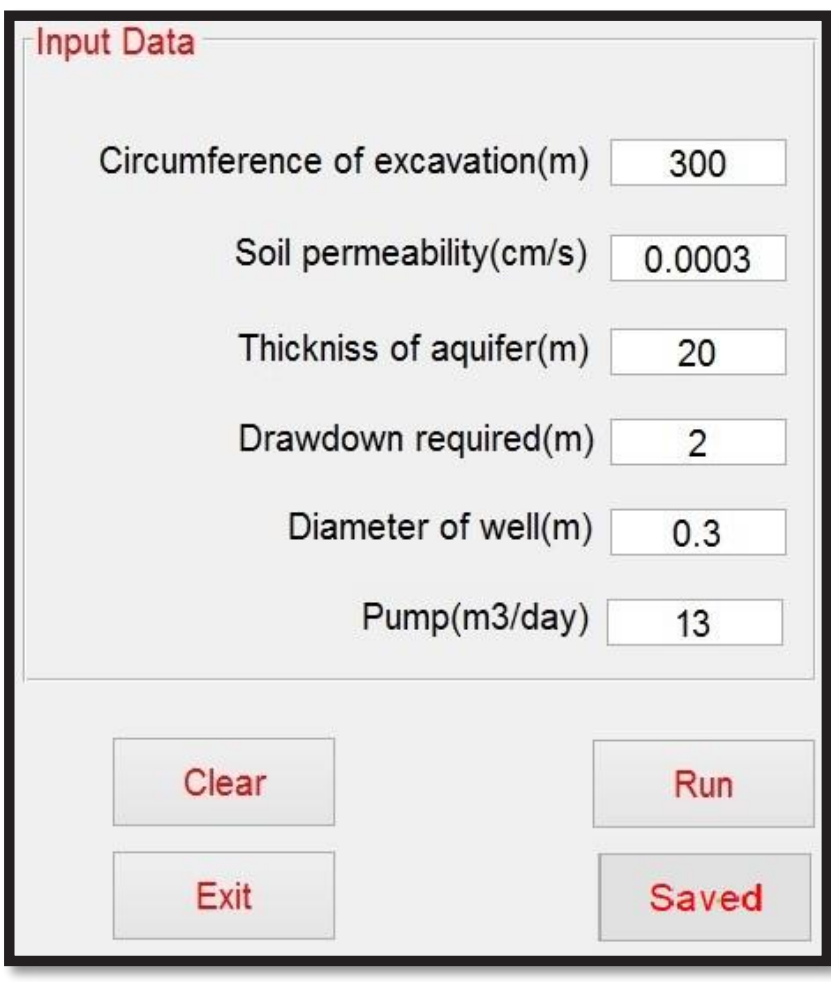

Figure 4. Input data of analyzed model.
Results

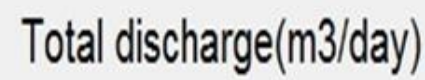

Influnce raduis(m)

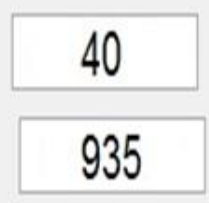

Number of

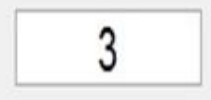

Distance between wells(m)

374

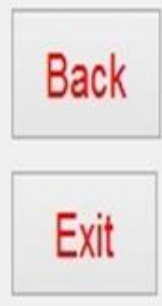

Figure 5. Result of analysis. 


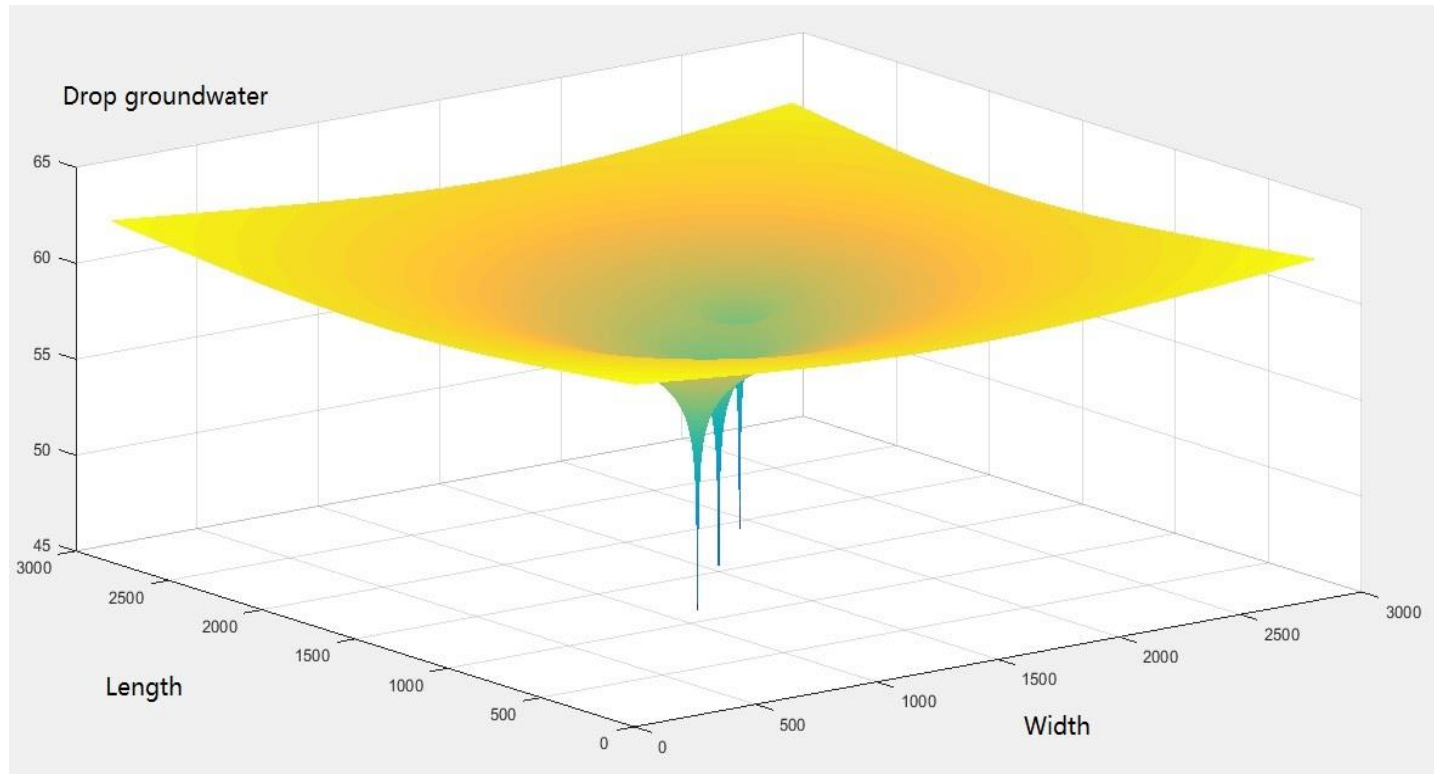

(a)

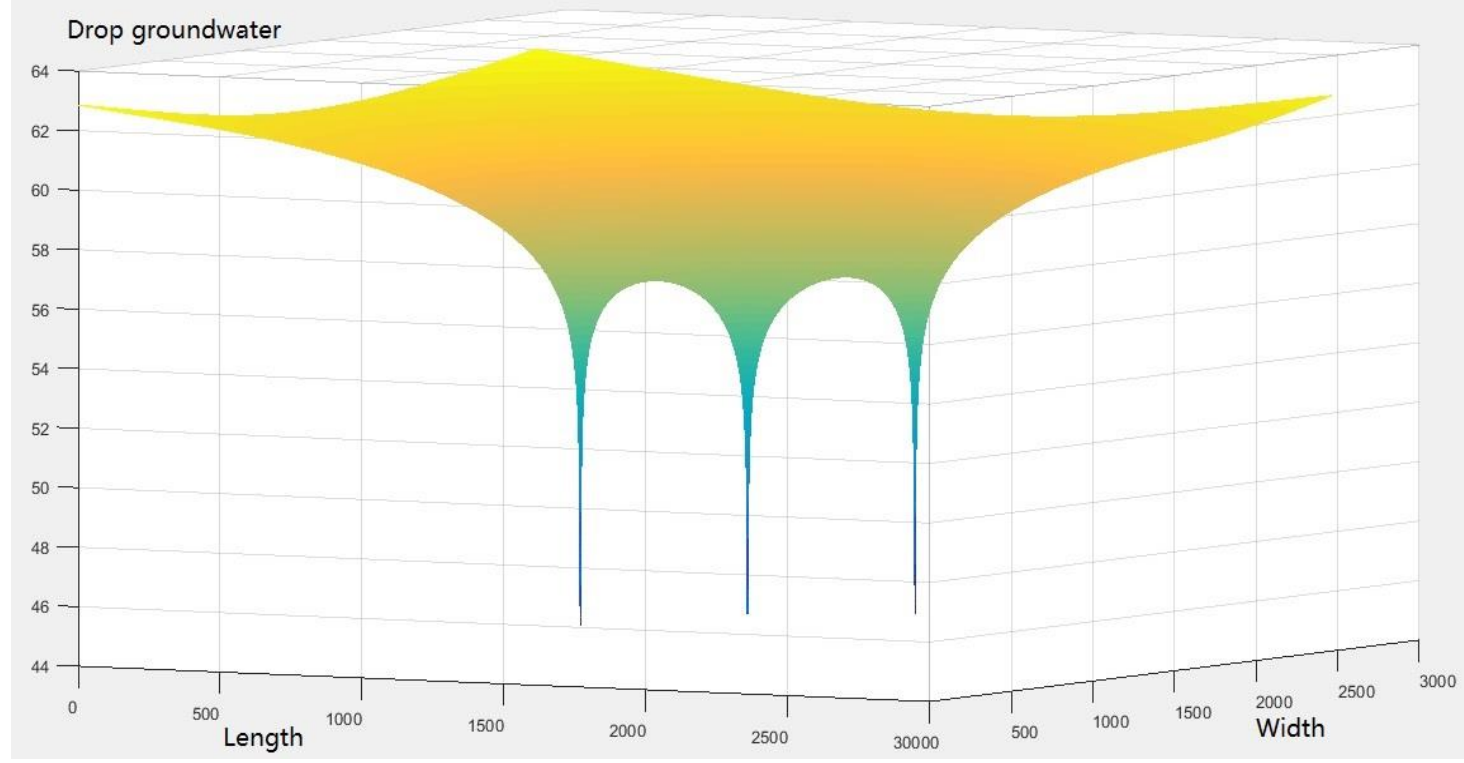

(b)

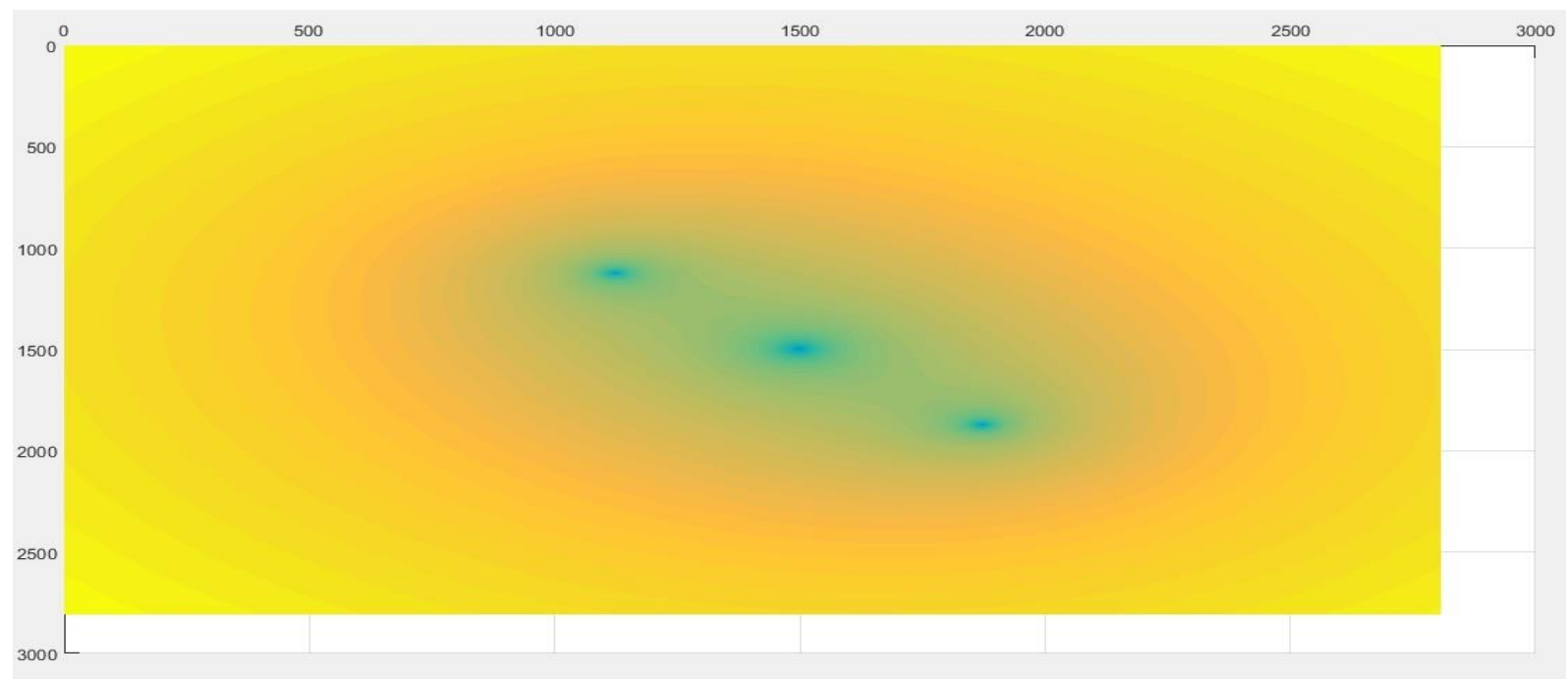

(c)

Figure 6. 3D modeling of wells, a) 3D model, b) 3D side view of wells, and c) Top view of wells. 


\section{Conclusions}

1) Building designs based on traditional experience cannot predict the effects of soil settlement or the probability of failure due to redistribution of stresses.

2) As an overall conclusion, it can be seen that by using the described model, risks of rising groundwater can be eliminated during construction. It is possible to have a better discussion with responsible persons in similar projects, and a better decision can be taken by using such a model.

3) The shape of the phreatic surface obtained from the program depends on the position of the wells as observed.

4) The program determines the radius of influence that is possible to know the neighboring buildings that entered within the influence of the groundwater withdrawal to take the necessary measures to preserve these buildings.

5) The selection of the diameter of wells and the specific capacity of pumping has a significant impact on the total discharge in the site.

\section{Reference}

[1] Ruilin, H., 2006. Urban land subsidence in China. Engineering geology for tomorrow's cities. Geological Society, London, Engineering Geology Special Publication, Paper 786.

[2] Ramadan, E.H., Ramadan, M., Khashila, M.M. and Kenawi, M.A., 2013. Analysis of piles supporting excavation adjacent to existing buildings. In Conference of Soil Mechanics and Geotechnical Engineering, pp. 2835-2838.

[3] El-Nahhas, F.M., 2003. Geotechnical aspects of controlling groundwater levels in urban areas. In A Keynote Paper, Proc. of the Tenth Int. Colloquium on Structural and Geotechnical Eng., Ain Shams Univ., Cairo (Vol. 6).

[4] Phienwej, N.G., Giao, P.H. and Nutalaya, N., 2006. Bangkok Land Subsidence. Engineering Geology, 82(4), pp.187-201.

[5] Bruce, D.A., 1994. Small-diameter cast-in-place elements for load-bearing and in situ earth reinforcement. Ground control and improvement, PP Xanthakos, LW Abramson, and DA Bruce, eds., Wiley Interscience, New York.

[6] Nemati, K.M., 2007. Temporary Structures, Construction Dewatering and Ground Freezing. University of Washington, Department of Construction Management.

[7] Tan, Y.P., Chen, J.J. and Wang, J.H., 2015. Practical investigation into two types of analyses in predicting ground displacements due to dewatering and excavation. Journal of Aerospace Engineering, 28(6), p.A4014001.

[8] Li, L. and Yang, M., 2008, December. Numerical evaluation of dewatering effect on deep excavation in soft clay. In Geotechnical Aspects of Underground Construction in Soft Ground: Proceedings of the 6th International Symposium (IS-Shanghai 2008) (p. 147). CRC Press.

[9] Budihardjo, M.A., Chegenizadeh, A. and Nikraz, H., 2014. Land subsidence: The presence of well and clay layer in aquifer. Australian Journalof Basic and Applied Sciences, 8, pp.217-224.

[10] Samaaneh, M. and Al-Gadhib, A., 2013. Modeling Impact of Dewatering on Soil Structure Interaction Using SAP. In Conference proceeding article.

[11] García-Ros, G., Alhama, I. and Cánovas, M., 2018. Powerful software to simulate soil consolidation problems with prefabricated vertical drains. Water, 10(3), p.242.

[12] Akgun, A., Sezer, E.A., Nefeslioglu, H.A., Gokceoglu, C. and Pradhan, B., 2012. An easy-touse MATLAB program (MamLand) for the assessment of landslide susceptibility using a Mamdani fuzzy algorithm. Computers \& Geosciences, 38(1), pp.23-34.

[13] Yousefi, H., Zahedi, S., Niksokhan, M.H. and Momeni, M., 2019. Ten-year prediction of groundwater level in Karaj plain (Iran) using MODFLOW2005-NWT in MATLAB. Environmental Earth Sciences, 78(12), pp.1-14.

[14] Wang, S., Shao, J., Song, X., Zhang, Y., Huo, Z. and Zhou, X., 2008. Application of MODFLOW and geographic information system to groundwater flow simulation in North China Plain, China. Environmental Geology, 55(7), pp.1449-1462. 
[15] Kollet, S.J. and Maxwell, R.M., 2008. Capturing the influence of groundwater dynamics on land surface processes using an integrated, distributed watershed model. Water Resources Research, 44(2).

[16] Luo, Z.J., Zhang, Y.Y. and Wu, Y.X., 2008. Finite element numerical simulation of threedimensional seepage control for deep foundation pit dewatering. Journal of Hydrodynamics, 20(5), pp.596-602.

[17] Reddi, L.N., 2003. Seepage in soils: principles and applications. John Wiley \& Sons.

[18] Yihdego, Y., 2018. Engineering and enviro-management value of radius of influence estimate from mining excavation. Journal of Applied Water Engineering and Research, 6(4), pp.329-337.

[19] Yihdego, Y. and Drury, L., 2016. Mine dewatering and impact assessment in an arid area: Case of Gulf region. Environmental monitoring and assessment, 188(11), pp.1-13.

[20] Yihdego, Y. and Paffard, A., 2017. Predicting open pit mine inflow and recovery depth in the Durvuljin soum, Zavkhan Province, Mongolia. Mine Water and the Environment, 36(1), pp.114123.

[21]Zhang, L., Zhou, X., Pan, Y., Zeng, B., Zhu, D. and Jiang, H., 2020. Design of Groundwater Extraction in Open Cut Foundation Pit and Simplified Calculation of Ground Subsidence due to Dewatering in Sandy Pebble Soil Strata. Advances in Civil Engineering, 2020. 